\title{
Os fluxos de comunicação do Corpo de Bombeiros: estudo de caso no interior do Rio Grande do Sul
}

\author{
Internal communication in the Fire Department: a case study in the interior of the \\ state of Rio Grande do Sul
}

\author{
Juliano Nunes Alves ${ }^{[\mathrm{a}]}$, Marcos Vinicius Lopes Bastide ${ }^{[\mathrm{b}]}$, Leander Luiz Klein ${ }^{[\mathrm{c}]}$ \\ [a] Mestre pela Universidade Federal de Santa Maria (UFSM), professor titular da Universidade de Cruz Alta (UNICRUZ), Santa \\ Maria, RS - Brasil, e-mail: admjuliano@yahoo.com.br \\ [b] Graduando pela Faculdade Integrada de Santa Maria, Santa Maria, RS - Brasil, e-mail: pesquisasufsm@gmail.com \\ [c] Graduando pela Universidade Federal de Santa Maria (UFSM), Santa Maria, RS - Brasil, e-mail: kleander88@gmail.com
}

\section{Resumo}

Este estudo constitui uma análise da percepção dos colaboradores em relação aos fluxos de comunicação interna numa organização pública, em que procurou-se verificar os pontos positivos e negativos na comunicação em instituições públicas, principalmente o caso do Corpo de Bombeiros. A pesquisa do tipo exploratório-descritiva foi desenvolvida no Corpo de Bombeiros de Santa Maria, interior do Rio Grande do Sul. Na coleta de dados, foram realizadas sete entrevistas com servidores da unidade, e foram examinadas por meio da análise de conteúdo. A partir da análise e interpretação dos dados, verificou-se que a organização não utiliza qualquer instrumento de avaliação ou controle da comunicação interna. Os fluxos de comunicação são deficientes a ponto de o servidor ser amparado apenas nos seus documentos formais e na burocracia, portanto não faz da comunicação uma ferramenta de gestão e não tem um fluxo contínuo e adequado. As falhas na comunicação incidem no retrabalho, no desperdício de recursos públicos, bem como no aumento do tempo para prestação dos serviços.

Palavras-chave: Comunicação interna. Fluxos de comunicação. Pontos positivos da comunicação. Pontos negativos da comunicação. 


\section{Abstract}

This study is an analysis of the perception of employees in relation to the flow of internal communication in a public organization, where the strengths and weaknesses in communication in public institutions were addressed, especially in the case of the Fire Department Institution. The research is an exploratory-descriptive study and it was developed in the Fire Department in Santa Maria, Rio Grande do Sul. Interviews were made for data collection, having seven employees of the fire unit as respondents, data from which were analyzed by content analysis. From the analysis and interpretation of data it was found that the organization does not use any instrument for assessment or control of internal communication, communication flow is deficient to the point the employee is supported only by his formal documents and paperwork, so communication is not used as a management tool and it does not have a continuous and adequate flow. Failures in communication can be verified as a determinant for reworking and waste of public resources, as well as increasing the time to performe services.

Keywords: Internal communication. Communication flows. Positive points of communication. Negative points of communication.

\section{Introdução}

A comunicação desde a antiguidade leva a uma melhor compreensão das informações e também uma melhora na qualidade de vida de todos os povos tornando-se, a cada dia, mais importante na relação da sociedade e dentro das empresas. Os processos comunicacionais sempre apresentaram uma evolução paralela àquela desenvolvida pelo homem, nos seus mais diferentes ambientes tomados, ou período histórico. Não há como desmembrar a forma de vida humana das práticas e formas do homem comunicar-se. Hoje, de forma mais ágil do que em outros tempos, os novos meios de comunicação continuam a aperfeiçoar a maneira de se comunicar, inclusive no ambiente interno das organizações (TORQUATO, 1986).

A comunicação é importante não só para organizações privadas, mas também para organizações públicas. A competitividade entre as organizações privadas faz dela uma ferramenta indispensável para esta se manter no mercado; já nas organizações públicas a comunicação é de muita importância para que ocorra uma prestação efetiva de serviços à sociedade. Mas, para que ela seja eficaz, se faz necessário que as organizações consigam que as informações alcancem todos os níveis (GOMES; MOURA; SANTOS, 2008). De semelhante maneira, não basta ter uma equipe de grandes talentos altamente motivados. Se ela não estiver bem informada, se seus integrantes não se comunicarem adequadamente, não será possível potencializar a força humana da empresa (RUGGIERO, 2002).
Uma das maiores dificuldades das organizações é levar as informações de forma clara aos colaboradores. Robbins (2005) diz que é necessário que a comunicação interna seja mais do que uma simples transferência de informações, pois falhas no processo podem acarretar conflitos dentro da empresa. Dessa forma, surge então o problema: O Corpo deBombeiros de Santa Maria está utilizando a comunicação interna como uma ferramenta eficaz de gestão que contribui para o alcance de sua missão?

Nesse contexto, o presente estudo tem como objetivo analisar a percepção dos integrantes do Corpo de Bombeiros de Santa Maria, no Rio Grande do Sul, em relação ao fluxo de comunicação organizacional. A justificativa para o estudo do tema decorre de dificuldades vivenciadas pelos integrantes dessa corporação, relacionadas ao modo como as informações são repassadas, pelo fato da comunicação estar ganhando espaço e se tornando, cada vez mais, parte do contexto decisório, mesmo que de forma incipiente e sem mostrar resultados expressivos em grande parte das instituições públicas e privadas (MEDEIROS, 2006).

\section{Referencial teórico}

\section{A comunicação organizacional}

Elo natural entre as organizações e os seus diversos públicos, a comunicação torna-se, cada vez 
mais, um elemento vital no processo das funções administrativas. Tanto no macroambiente, quanto no universo interno, a comunicação é a dinâmica que assegura a interligação de todos os elementos integrantes de uma organização, ou seja, a coordenação dos recursos humanos, financeiros e materiais. Segundo Kunsch (2003, p. 69), a comunicação organizacional trata-se de um processo que estabelece as relações entre as pessoas, unidades e até outras organizações sociais.

De modo geral, o sucesso de uma empresa começa primeiro em sua instância interna, a partir das habilidades de comunicação de que ela dispõe. Não somente o apoio, mas o envolvimento efetivo tanto da alta administração e de todos os seus funcionários - em diferentes graus, em diferentes contextos e conexões - para desenvolver as operações básicas de uma organização. Apesar da al ta tecnologia, o mundo continua a exigir a atenção dos administradores em relação às pessoas, suas habilidades e competências (SCHERMERHORN, 1999).

Assim, entende-se por comunicação interna o esforço de comunicação desenvolvido por uma organização, empresa, órgão ou entidade para estabelecer canais, como jornais, boletins, relatórios, cartas, manuais, entre outros, que possibilitem o relacionamento ágil e transparente da alta administração com os demais indivíduos que fazem parte do público interno, além de envolver a comunicação entre os próprios atores sociais que integram esse público (Robbins, 1998). Segundo Robbins (2005), o processo de comunicação é composto de sete partes: a fonte de comunicação, a codificação, a mensagem, o canal, a decodificação, o receptor, o ruído e o feedback. Feedback é o procedimento de fornecer informação a uma pessoa sobre o desempenho, conduta ou eventualidade executada por ela. A fonte inicia a mensagem pela codificação de um pensamento, a mensagem é o produto físico codificado pelo emissor. O canal é a mídia por onde a mensagem viaja, ele é selecionado pelo emissor, que deve determinar qual canal é formal e qual é informal. Os canais formais são estabelecidos pela organização e transmitem mensagens que se referem às atividades relacionadas com o trabalho de seus membros, os canais informais são espontâneos e surgem como resposta às escolhas individuais.

No processo de comunicação, o indivíduo que deseja enviar a mensagem necessita 'traduzir os símbolos' da mensagem de forma que ela possa ser compreendida pelo receptor, sujeito a quem a mensagem se dirige. Tornar a mensagem o mais clara possível para o receptor diminui o chamado 'ruído', que são as barreiras à comunicação que distorcem a mensagem e dificultam a compreensão. $\mathrm{O}$ elo final do processo de comunicação é o círculo de feedback, quando é realizada a constatação de que a transmissão da mensagem como planejada foi realizada com sucesso.

Conforme Kotler (2000), para promover uma comunicação eficiente, é necessário compreender os principais elementos que compõem essa comunicação. Dois deles representam as principais partes envolvidas na comunicação: o emissor e o receptor; outros dois representam as principais ferramentas de comunicação: a mensagem e o meio; e outros quatro elementos representam as principais funções da comunicação: codificação, decodificação, resposta e feedback. O último elemento do processo se refere ao ruído, que correspondeà mensagens aleatórias e concorrentes que podem interferir na comunicação pretendida.

\section{Fluxos da comunicação}

Os fluxos comunicacionais internos comparam-se a um organograma típico em que a comunicação formal possui linhas horizontais e verticais, sendo estas classificadas nos sentidos descendente e ascendente (MARIN, 1997). Para Torquato (2004), "são eles que constituem os caminhos, os desvios e os degraus que atravessam a comunicação". Além dos três tipos mais comuns de fluxo - descendente, ascendente, horizontal/lateral-Torquato (2004) cita ainda o fluxo diagonal da comunicação.

\section{Fluxo de comunicação vertical descendente}

Kunsch (2003) e Maximiano (2000) afirmam que os objetivos do fluxo de comunicação vertical descendente estão relacionados à transmissão da filosofia, das normas, e das diretrizes da organização, além da emissão de ordens e informações repassadas sobre políticas e programas que a administração pretende implantar.

Marin (1997) enfatiza que esse fluxo de comunicação, tido como o mais importante para a 
direção da organização, torna-se causa frequente de problemas, tais como: saturação de informações nos canais que fazem este tipo de comunicação; ordens comunicadas às pressas e vagamente e comunicação realizada sem precisão em virtudes do termos muito técnicos ou sem critérios. Ou seja, o fluxo de comunicação apresenta distorções na sua execução em virtude de sua prática rotineira. Na visão de Torquato (2004), isso tem grande importância do ponto de vista da gestão organizacional, pois funciona como ferramenta para direcionar o comportamento da organização e suas equipes, no que diz respeito às suas estratégias e metas.

\section{Fluxo de comunicação vertical ascendente}

$\mathrm{Na}$ visão de Marin (1997), para que ocorra um fluxo de comunicação ascendente sem colapsos, é necessário um certo grau de institucionalização, por meio da utilização de instrumentos planejados como: caixa de sugestões, concurso de ideias e participação recompensada com benefícios. Para Torquato (2004), esseprocedimentoécaracterizado portrazeremseubojo as inquietudes, sugestões, críticas, necessidades e apelos dos empregados para os altos escalões da organização.

Em muitos casos, por meio da comunicação ascendente que os dirigentes tomam conhecimento dos problemas e do cotidiano operacional da organização. Em contrapartida, Neves (1998) ressalta que o fluxo da comunicação "de baixo para cima" corre o risco de tornar-se menos confiável quando a informação é comumente filtrada pela média gerência antes de chegar à alta administração.

\section{Fluxo de comunicação horizontal}

Marin (1997) considera que a comunicação horizontal é aquela que se dá entre as pessoas consideradas iguais, hierarquicamente, em uma organização. Nesse sentido, Maximiano (2000), define a comunicação horizontal como aquela que ocorre entre unidades de trabalho do mesmo nível ou entre unidades de trabalho de níveis diferentes, também chamada de comunicação diagonal pelo autor. Já Kunsch (2003) salienta a importância desse fluxo pelo papel agregador que proporciona a socialização de informações, assim como o conhecimento de atividades das outras unidades organizacionais.
As características da comunicação horizontal permitem também que ela oriente a rede informal, facilite a tomada de decisões e promova a integração interdepartamental (TORQUATO, 2004). Marin (1997) destaca algumas dificuldades da comunicação horizontal, como o fato de muitas vezes os membros ficarem isolados em suas próprias áreas de atividade e sem tempo ou estímulo para as tarefas de coordenação.

\section{Fluxo de comunicação diagonal}

A comunicação diagonal, ou transversal, acontece em geral com a troca de mensagens entre um superior e um subordinado em outra área/departamento. Sua presença é mais comum em organizações flexíveis, cuja gestão é mais participativa e integrada, com menos burocracia e forte peso nos programas interdepartamentais (TORQUATO, 2004).

$\mathrm{O}$ ato de comunicar é uma maneira de interação e de diálogo visando a tornar algo comum. Não pode ser confundida com a simples transmissão unilateral de informações. Mas, no ambiente das organizações, a dimensão da comunicação pode estar reduzida a um instrumento de divulgação de determinados acontecimentos e de controle, o que se descaracteriza da sua função principal, que é a integração entre as pessoas (TORQUATO, 2004).

Para Stoner e Freeman (1999, p. 338), a comunicação é o processo por meio do qual os administradores realizam suas funções de planejamento, organização, liderança e controle. Por isso, a comunicação passa a ser uma atividade fundamental para os administradores. Em virtude de a comunicação poder ocorrer de forma descendente e ascendente, percebe-se que, no âmbito organizacional, a comunicação, no duplo sentido, torna-se mais eficiente pelo fato de se obter uma resposta por parte do receptor. Isto permite aos superiores receberem informações de seus subordinados, fornecendo informações adequadas do que realmente está acontecendo na empresa.

\section{Método de pesquisa}

Considerando que o objetivo da presente pesquisa é analisar a percepção dos colaboradores quanto à comunicação interna, optou-se, para este propósito, pela pesquisa qualitativa, definida por Neves (1996), em linhas 
gerais, como sendo a pesquisa que detecta a presença ou não de algum fenômeno, sem se importar com sua magnitude ou intensidade. É denominada qualitativa em contraposiçãoà pesquisa quantitativa, em funçãoda forma como os dados serão tratados e da forma de apreensão de uma realidade, em que, no caso da pesquisa qualitativa, o mundo é conhecido por meio de experiência e senso comum (conhecimento intuitivo), em oposição às abstrações (modelos) da pesquisa quantitativa. Os métodos qualitativos e quantitativos não são excludentes, embora difiram quanto à forma e à ênfase (NEVES, 1996).

Tendo presente os procedimentos técnicos que foram utilizados na pesquisa, o método utilizado foi o estudo de caso. Este permite examinar aspectos variados do problema, como a facilidade de acesso às informações, além de fornecer uma maior flexibilidade na análise, já que não há um esquema conceitual rígido. Dessa forma, Yin (2005, p. 32) diz que o estudo de caso "investiga um fenômeno contemporâneo dentro de seu contexto da vida real", ou seja, esse método permite um melhor conhecimento da realidade.

A análise da comunicação será feita pormeio daidentificação dos canais e fluxos utilizados na organização. Para isso, foi elaborada uma entrevista semiestruturada. As entrevistas costumam ser os instrumentos mais utilizados em pesquisas qualitativas, pois têm como objetivo levantar a opinião de pessoas ou grupos selecionados para posterior análise exploração das informações obtidas. Segundo Medina (1995), a entrevista pode ser uma técnica de interação social e interpretação informativa, além de servirà distribuição democrática deinformações.

Para Duarte (2005), a entrevista é uma técnica clássica para obter informações nas Ciências Sociais, muito utilizada em áreas como Psicologia, a Sociologia, a Administração e a Comunicação. Por meio das perguntas, o assunto escolhido pode ser explorado e aprofundado. Os dados obtidos servem para compreender o passado, analisar, discutir e sugerir propostas de melhorias. As entrevista servem ainda para "identificar problemas, micros interações, padrões e detalhes, obter juízos de valor e interpretações, caracterizar a riqueza de um tema e explicar fenômenos de abrangência limitada (DUARTE, 2005, p. 63).

\section{Análise dos resultados}

A partir dos resultados, verificaram-se os fluxos de comunicação do Corpo de Bombeiros no interior do Rio Grande do Sul. Além disso, pôde-se demonstrar cada ponto positivo e negativo desse fluxo na respectiva organização pública pesquisada.

\section{Fluxo das informações}

Além dos três tipos mais comuns de fluxo de comunicação - descendente, ascendente, horizontal/lateral - Torquato (2004) cita ainda o fluxo diagonal da comunicação. Neste sentido buscou-se identificar a existência ou não do fluxo ascendente, bem como buscou-se também avaliar a importância dada ao processo de feedback.

\section{a) Fluxo Ascendente}

Para Torquato (2004) o fluxo de comunicação ascendente pode estar presente em alguns canais formais de comunicação, como as caixas de sugestões, seção de cartas ao leitor, em murais ou jornais internos, encontros com os dirigentes e até mesmo em pesquisas de clima organizacional, mas também permeia a rede informal.

Neste sentido, alguns relatos colaboram para identificá-lo, perguntado aos entrevistados, quando algo não está correto nos bombeiros, com quem eles conversam: "Com colegas e superiores imediatos, em tom de crítica" (Entrevistado 1). "Converso com colegas e superiores" (Entrevistado 5). "Primeiramente com colegas e depois com superiores dependendo" (Entrevistado 6).

Nota-se, a partir dos relatos, a existência e o poder dos fluxos ascendente e lateral exercendo influência sobre a eficácia do processo comunicativo. Tal análise destaca ainda um padrão de informalidade nos relacionamentos.

Segundo Pretto (2000), a interação pessoal direta possibilita receber e dar feedback, o que permite o monitoramento e a intervenção sobre manifestações e expressões dos sujeitos participantes da relação comunicacional. Questionou-se aos colaboradores a importância da comunicação direta e das reuniões com seus superiores. Os relatos a seguir evidenciam isso: "São importantes e deveriam ser mais frequentes" (Entrevistado 1). "Existem mas geralmente para a execução do serviço, e não para o melhoramento. São importantes mas deveriam acontecer com mais frequência" (Entrevistado 3).

Os relatos reforçam a evidência da valorização da comunicação face a face com seus superiores, cuja interação acontece quando as partes envolvidas 
participam do mesmo contexto físico. Nesse tipo de comunicação, que, normalmente, ocorre a partir de diálogos, reuniões, seminários ou grupos de trabalho, há a otimização do processo pela facilidade e rapidez na troca de informações. Torna-se possível perceber, por exemplo, por meio de linguagem verbal e não verbal, manifestações, mesmo que sutis do sujeito. Isso, por sua vez, permite que o emissor antecipe, aproximadamente, o que ocorrerá durante a comunicação.

b) O feedback da comunicação

Segundo Beltrão (1973), para obter melhor qualidade da comunicação humana, emissor e receptor devem estar em sintonia. Ou seja, quanto mais pontos comuns entre ambos, melhor será a qualidade da comunicação. No processo de comunicação nas suas múltiplas etapas, sempre acontece o retorno (feedback), pelo qual se pode avaliar a interpretação da mensagem o emissor torna-se receptor e o receptor torna-se emissor, sujeito a todos os problemas de emissores, receptores e transmissão. Neste sentido, perguntado qual a percepção dos entrevistados com relação ao processo de feedback no sistema de comunicação com os superiores. "As opiniões são ignoradas, sugestões ouvidas somente e as dúvidas são tiradas na medida da necessidade" (Entrevistado 2). "Existem vários tipos de superiores, mas via de regra eles não escutam opiniões sugestões ou dívidas" (Entrevistado 3). "Raramente uma opinião chega a algum lugar" (Entrevistado 7). Nota-se, a partir das entrevistas, que de uma maneira geral, a organização não valoriza o feedback da comunicação, dúvidas, sugestões e opiniões não são valorizadas e respondidas.

\section{A importância da comunicação}

Para Piccin, (2008), a comunicação interna não apenas informa seus beneficiários, voluntários e colaboradores, mas tem também como objetivo o de despertar diariamente nas pessoas a vontade e o orgulho de fazerem parte da instituição, o sentimento de que fazem parte do trabalho em sua totalidade. Dos servidores entrevistados que responderam sobre a contribuição da comunicação interna para que o corpo de bombeiros alcance sua missão institucional: a maioria considerou-a indispensável.

"É imprescindivel, tem que haver uma boa comunicação" (Entrevistado 2).
É muito importante, porque na medida em que ocorre a comunicação efetiva, no caso do meu departamento, por exemplo, vocêcompra que o efetivo estaprecisando, vocêtem o equipamento que será melhor empregado e o serviço será prestado damelhorformapossivel(Entrevistado3). "Ela é indispensável em qualquer lugar" (Entrevistado 6).

Portanto, percebe-se que, sem uma comunicação adequada, a motivação dos funcionários, ou seja, sua vontade e o orgulho de fazerem parte se compromete. É importante encontrar formas de abranger a comunicação interna aos colaboradores, disponibilizá-la e torná-la mais acessível e saber das necessidades deste servidor.

Ressalta-se Tavares (2007), que acredita que a comunicação interna, além de atender objetivos diretos da empresa, serve para motivar e integrar o público interno e logo, se ela não ocorre de forma planejada, gera descontentamento da equipe e soa como falta de preocupação da empresa com o quadro funcional. Alguns relatos contribuem para nesse sentido:

"Na medida em que necessito de informações para o men serviç tenho que buscar, tenho que procurar, correr atrás" (Entrevistado 2). "Tenho que buscar as informações que preciso, as informações que tenho, chegam em medida muito menor do que realmente preciso" (Entrevistado 3).

Nesse sentido, os relatos demonstraram que, na medida em que os servidores sentem a necessidade de informações, não existe um procedimento estipulado pela organização para troca de informações, portanto não há uma preocupação quanto ao grau de informação existente para os colaboradores.

Nesse processo comunicativo, podem ocorrer falhas, o que, para Santos (1980, p. 34), está atribuído à "complexidade do comportamento humano". Para este autor, alguns fatos podem contribuir para que ocorram falhas na comunicação, tais como: o estado emocional, os preconceitos, a autossuficiência, o meio, a diferença de interesses, a religião, o status, a especialização, a educação, a cultura, o sexo, a idade e a diferença entre a realidade do emissor e a do receptor.

Já para Torquato (2004), as distorções e falhas mais comuns no sistema de comunicação têm origem em fatores como: inadequação de canais, inadequação 
de linguagens, ausência de tempestividade, excesso de informações, planejamento inadequado do consumo informativo e falta de especialistas.

A comunicação sem falhas, sema interferência daquilo que se convencionou por "ruído", acontece quando o receptor decodifica a mensagem da mesma maneira que ela foi codificada pelo seu emissor, no tempo certo. Neste sentido, os relatos a seguir demonstram essas percepções:

Falhas existem com frequência, as pessoas que operam o radio transmissor não tem a capacidade (Entrevistado 1). Falhas acontecem frequentemente e o problema é o prazo, o tempo, informações fora do tempo (Entrevistado 2). Acontecem, geralmente acontecem às falhas na comunicação no corpo de bombeiros e com frequência, por que não existe um canal explícito de informações, um canal lógico de informações (Entrevistado 3).

Observa-se, por meio destes relatos, que as falhas na comunicação interna do Quarto CRB acontecem frequentementee dentre os principais motivos estão à falta de treinamento do efetivo para a comunicação, e atrasos quanto a prazos previstos.

\section{Pontos positivos e negativos da comunicação}

A partir da caracterização da comunicação, podem-se identificar alguns pontos positivos e negativos do processo, os quais são melhor descritos nos Quadros 1 e 2, respectivamente:

Quadro 1 - Pontos negativos

\begin{tabular}{ll}
\hline Componentes & Aspectos negativos \\
\hline $\begin{array}{l}\text { Fluxo de } \\
\text { informações } \\
\text { ascendente }\end{array}$ & $\begin{array}{l}\text { A desvalorização deste fluxo } \\
\text { que serve como feedback da } \\
\text { comunicação, se bem utilizado ele é } \\
\text { um meio que leva até os dirigentes } \\
\text { o conhecimento dos problemas do } \\
\text { cotidiano operacional. }\end{array}$ \\
$\begin{array}{l}\text { Fluxo de } \\
\text { informação } \\
\text { descendente }\end{array}$ & $\begin{array}{l}\text { burocráticos e apresenta } \\
\text { predominantemente o fluxo } \\
\text { horizontal descente, tornando } \\
\text { a comunicação interna pouco } \\
\text { envolvente aos seus colaboradores. }\end{array}$ \\
\hline
\end{tabular}

Quadro 1 - Pontos negativos

\begin{tabular}{ll} 
Componentes & Aspectos negativos \\
\hline $\begin{array}{l}\text { Nivel de } \\
\text { informação }\end{array}$ & $\begin{array}{l}\text { Na medida em que os servidores } \\
\text { sentem a necessidade de } \\
\text { informações, não existe um } \\
\text { procedimento estipulado pela } \\
\text { organização para troca de } \\
\text { informações, portanto não há } \\
\text { um controle quanto ao grau de } \\
\text { informação existente para os } \\
\text { colaboradores } \\
\text { As falhas na comunicação interna } \\
\text { do Quarto CRB acontecem } \\
\text { frequentemente e dentre os } \\
\text { principais motivos estão a falta } \\
\text { de treinamento do efetivo para a } \\
\text { comunicação, e atrasos quanto a } \\
\text { prazos previstos. }\end{array}$ \\
\hline
\end{tabular}

Fonte: Dados da pesquisa.

Nota-se, a partir do Quadro 1, algumas das dificuldades encontradas na organização quanto a comunicação interna, existindo também aspectos positivos melhor descritos no Quadro 2.

Quadro 2 - Pontos positivos

\begin{tabular}{ll}
\hline Componentes & Aspectos positivos \\
\hline $\begin{array}{l}\text { A importância da } \\
\text { comunicação }\end{array}$ & $\begin{array}{l}\text { A partir das entrevistas, } \\
\text { nota-se que os } \\
\text { colaboradores consideram } \\
\text { a comunicação interna } \\
\text { fator indispensável para a } \\
\text { organização atingir sua meta. }\end{array}$ \\
Confiabilidade dos & $\begin{array}{l}\text { A partir da análise dos } \\
\text { resultados, pode-se observar } \\
\text { que os colaboradores confiam } \\
\text { mais na informação sobre a } \\
\text { corporação quando ela vem } \\
\text { por meio de documentos. }\end{array}$ \\
\hline
\end{tabular}

Fonte: Dados da pesquisa.

Visando a uma comunicação interna mais eficaz e útil à organização, podem-se propor algumas 
melhorias relevantes. Sugere-se que sejam adotadas práticas de comunicação interna, mais focadas e abrangentes como: criar um jornal ou informativo circular sobre o setor de RH e matérias com destaque à integração com a organização, e informativos com datas festivas de aniversários dos colaboradores.

Sugere-se ainda facilitar e promover a comunicação nos dois sentidos. Se houver a possibilidade de se efetuar uma comunicação ascendente de forma efetiva, melhora-se a comunicação, já que programas ineficazes são denominados por comunicações descendentes. Otimizar o uso dos recursos já existentes, seja por meio do aumento e controle da frequência com que as informações são distribuídas ou mesmo por meio da adoção de um canal prioritário com um melhor apelo visual, tornando-o, assim, mais atrativo.

Sugere-se também a construção de um planejamento estratégico em comunicação, a partir da elaboração de um diagnóstico e acompanhado da implantação de um plano de ação.

\section{Considerações finais}

Embora a comunicação ganhe cada vez mais um papel estratégico nas organizações, como ferramenta de gestão, na construção e no fortalecimento dos relacionamentos com seus diversos públicos, o que a pesquisa aponta é que, na organização pública pesquisada, a comunicação ainda não é utilizada dessa forma, limitando-se ao seu caráter administrativo e com o objetivo maior de dar publicidade aos atos e ações institucionais.

Possuindo caráter militar e espelhada nas Instruções Gerais do Exército Brasileiro, a comunicação é pouco envolvente aos seus colaboradores, utiliza-se de meios muito burocráticos e apresenta predominantemente, na sua formalidade, o fluxo horizontal descendente, tornando a comunicação pouco eficaz. Percebe-se, ainda, que não há, na organização pública, qualquer instrumento de avaliação ou controle da comunicação interna existente.

Sem a presença de um canal formal prioritário de comunicação interna, ou o uso de qualquer tecnologia no sentido de possibilitar um fluxo às informações mais efetivo, o processo comunicativo na organização pública pesquisada se desenvolve principalmente por meio de vários canais ao mesmo tempo e apontado ainda como insatisfatório para o público interno que demonstrou que confia mais na informação quando ela vem por meio de documentos.

Torna-se importante salientar que a organização pesquisada reconhece a comunicação como um importante elemento de integração e fator de desenvolvimento organizacional, o que corrobora para necessidade de torná-la uma ferramenta estratégica de gestão, contribuindo cada vez mais para que a organização alcance sua missão institucional.

\section{Referências}

BELTRÃO, L. Fundamentos científicos da comunicação. Brasília: Thesaurus, 1973.

DUARTE, J. Entrevista em profundidade. In: DUARTE, J.; BARROS, A. (Org.). Métodos e técnicas de pesquisa em comunicação. São Paulo: Atlas, 2005. p. 62-82.

KOTLER, P. Administração de marketing: a edição do novo milênio. Tradução Bazán Tecnologia e Linguística. São Paulo: Prentice Hall, 2000.

KUNSCH,M.M.K. Planejamento de relações públicas na comunicação integrada. São Paulo: Summus, 2003.

MAXIMIANO, A. C. A. Introdução à administração. São Paulo: Atlas, 2000.

MEDEIROS, R. A comunicação interna numa organização pública. 2006. 86 f. Dissertação (Mestrado em Administração) - Universidade Federal do Rio Grande do Norte, Natal, 2006.

MEDINA, C. Entrevista: o diálogo possível. São Paulo: Ática, 1995.

GOMES, F. D.; MOURA, G. J.; SANTOS, N. C. O. A importância da comunicação em organizações públicas. Disponível em: <http:/ / www.portal-rp.com.br/ projetosacademicos/organismospublicos01/0116.pdf>. Acesso em: 20 dez. 2008.

MARÍN, A. L. La comunicación en la empresa e en las organizaciones. Barcelona: Bosch, 1997.

NEVES, J. L. Pesquisa qualitativa: características, usos e possibilidades. Caderno de Pesquisas em Administração, v. 1, n. 3, 1996. Disponível em: < http://www.ead. fea.usp.br/cad-pesq/arquivos/c03-art06.pdf>. Acesso em: 20 dez. 2008. 
NEVES, R. C. Imagem empresarial: como as organizações (e as pessoas) podem proteger e tirar proveito seu maior patrimônio. Rio de Janeiro: Mauad, 1998.

PRETTTO, C. B. M. A auto-organização do sistema cultural sindical, através do processo comunicacional negocial. In: CONGRESSO BRASILEIRO DE CIÊNCIAS DA COMUNICAÇÃO, 23., 2000, Manaus. Anais... Manaus: Congresso Brasileiro de Ciências da Comunicação, 2000.

PICCIN, P. A importância da comunicação em Organizações nãogovernamentais.2008.Disponívelem: $<$ http:/ / www.comtexto.com.br/2convicomcctsPaulaPiccin.htm>. Acesso em: $1^{\circ}$ dez. 2011.

ROBBINS, S. P. Comportamento organizacional. Rio de Janeiro: LTC, 1998.

ROBBINS, S. P. Comportamento organizacional. Tradução de Reynaldo C. Marcondes. 11. ed. São Paulo: Pearson Prentice Haal, 2005.

RUGGIERO, A. P. Qualidade da comunicação interna. 2002. Disponível em: <http://www.rh.com.br>. Acesso em: 28 ago. 2006.

SANTOS, E. R. M. Comunicação na pequena, média e grande empresa. Rio de Janeiro: Tecnoprint, 1980.
SCHERMERHORN Jr., J. R. Fundamentos do comportamento organizacional. 2. ed. Porto Alegre: Bookman, 1999.

STONER, J. A. F.; FREEMAN, R. E. Administração. Tradução de Alves Calado. 5. ed. Rio de Janeiro: LTC,1999.

TAVARES, M. Comunicação empresarial e planos de comunicação: integrando teoria e prática. São Paulo: atlas, 2007.

TORQUATO, G. Comunicação Empresarial / Comunicação Institucional: conceitos, estratégias, sistemas, estrutura, planejamento e técnicas. São Paulo: Summus, 1986.

TORQUATO, G. Tratado de comunicação: organizacional e política. São Paulo: Pioneira Thomson Learning, 2004.

YIN, R. K. Estudo de caso: planejamento e métodos. Tradução de Daniel Grassi. 3. ed. Porto Alegre: Bookman, 2005.
Recebido: 29/02/2012

Received: 02/29/2012

Aprovado: 01/06/2012 Approved: 06/01/2012 
